\title{
Using a computational model to quantify the potential impact of changing the placement of healthy beverages in stores as an intervention to "Nudge" adolescent behavior choice
}

Michelle S. Wong ${ }^{1,2^{*}}$, Claudia Nau', Anna Yevgenyevna Kharmats ${ }^{1,3}$, Gabriela Milhassi Vedovato ${ }^{4}$, Lawrence J. Cheskin ${ }^{1,5,6}$, Joel Gittelsohn ${ }^{1,7}$ and Bruce Y. Lee ${ }^{1,3}$

\begin{abstract}
Background: Product placement influences consumer choices in retail stores. While sugar sweetened beverage (SSB) manufacturers expend considerable effort and resources to determine how product placement may increase SSB purchases, the information is proprietary and not available to the public health and research community. This study aims to quantify the effect of non-SSB product placement in corner stores on adolescent beverage purchasing behavior. Corner stores are small privately owned retail stores that are important beverage providers in low-income neighborhoods - where adolescents have higher rates of obesity.

Methods: Using data from a community-based survey in Baltimore and parameters from the marketing literature, we developed a decision-analytic model to simulate and quantify how placement of healthy beverage (placement in beverage cooler closest to entrance, distance from back of the store, and vertical placement within each cooler) affects the probability of adolescents purchasing non-SSBs.

Results: In our simulation, non-SSB purchases were 2.8 times higher when placed in the "optimal location" - on the second or third shelves of the front cooler - compared to the worst location on the bottom shelf of the cooler farthest from the entrance. Based on our model results and survey data, we project that moving non-SSBs from the worst to the optional location would result in approximately 5.2 million more non-SSBs purchased by Baltimore adolescents annually.
\end{abstract}

Conclusions: Our study is the first to quantify the potential impact of changing placement of beverages in corner stores. Our findings suggest that this could be a low-cost, yet impactful strategy to nudge this population-highly susceptible to obesity - towards healthier beverage decisions.

Keywords: Obesity, Corner store intervention, Sugar sweetened beverage consumption

\footnotetext{
* Correspondence: Mwong23@jhu.edu

${ }^{1}$ Global Obesity Prevention Center (GOPC) and Johns Hopkins, Johns Hopkins

School of Public Health, 615 N. Wolfe St, Baltimore, MD 21205, USA

${ }^{2}$ Department of Health Policy and Management, Johns Hopkins School of

Public Health, 624 N. Broadway, Baltimore, MD 21205, USA

Full list of author information is available at the end of the article
} 


\section{Background}

While manufacturers, particularly sugar sweetenedbeverage (SSB) companies, expend considerable amount of effort, time, and resources determining where to place their products in stores to maximize purchasing [1], most of this research is proprietary and unavailable to the broader research community. Public health could potentially take advantage of product placement to curb SSB consumption, which is linked to obesity risk [2]. This strategy of product placement takes advantage of the fact that consumers may subconsciously rely on environmental cues - such as visibility, accessibility, and convenience - to help guide their purchasing decisions $[3,4]$. Placing healthier beverage options in more visible and easily accessible locations, public health can potentially "nudge" consumers away from SSBs without limiting their range of beverage choices by making these healthier choices more appealing [4].

This study aims to quantify the effect of non-SSB product placement in corner stores on adolescent beverage purchasing behavior. We developed a computational simulation model to address this. "Nudging" strategies, including product placement, tend to be relatively simple and easy to implement [4], making them ideal for settings with limited resources, such as corner stores.

\section{Methods}

We developed a decision-analytic computer simulation model in TreeAgePro 2014 (TreeAge Pro, Williamstown, MA) to quantify the impact of changing non-SSB (e.g., bottled water) placement in corner stores on adolescent non-SSB purchases. Prior research suggests that the effect of marketing strategies, such as product placement, varies by consumer preferences [5]. Product placement strategies include placement in the first cooler, vertical placement within a cooler, and horizontal distance from the back of the store [6-8].

Figure 1 displays the model structure. Table 1 provides input parameters and data sources. We modeled 6 coolers, each with 6 shelves, which are labeled numerically by location (cooler 1 was closest to the entrance, and shelf 1 was the top). Information about cooler location came from an assessment of 29 corner stores conducted by the B'more Healthy Communities for Kids (BHCK) program, an obesity prevention program in Baltimore, Maryland [9]. More information about the BHCK program is available from in Gittelsohn et al. (2014) [9]. Information about cooler width came from online searches of retail beverage coolers dimensions [10].

Adolescents are assigned to one of four beverage preference groups based on their probability of purchasing an SSB: always, usually, sometimes, rarely/never. This data came from beverage purchasing data from BHKC's sample of 211 predominantly low-income African American adolescents, ages 10 to 14 , who purchased at least one beverage from a corner store during the prior week. Preference groups were assigned based on quartiles of the proportion of non-SSB beverages purchased.

Based on baseline preference, individuals are further classified into "convenience shoppers" who only walk to the first cooler (cooler 1), or "browsers" who also check the remaining coolers (cooler $2-6$ ). We assume that "always" and "never SSB" drinkers are more likely to be browsers than "sometime" or "usually SSB" drinkers. The probability of being a browser or convenience shopper came from a study that assessed the effect of food order in a buffet line on diner food selection [11]. We vary this probability by a beverage-preference-specific "loyalty" parameter, obtained from data on the effect of consumer brand loyalty on brand-switching behavior [5].

All individuals are assumed to be influenced by a "vertical effect": distance to the middle and bottom shelf. Browsers are also influenced by the "horizontal effect" of distance to the back of the store. Vertical and horizontal effect parameters came from an observational study of product placement on canned soups sales [7]. We assumed that these effects would be similar for a range of products, including beverages.

We assume that adolescents only purchase one beverage per store visit; and beverages are the same price and size and have the same number of facings (i.e., amount of shelf space allotted to a product). Based on CDC's definition, non-SSBs include: water, diet soda and soft drinks, $100 \%$ fruit juice, and milk, while SSBs include non-diet soft drinks/sodas, sweetened fruit juices, and caloric sports drinks [12].

We simulate purchases by 1000 individuals. We calculated the probability of purchase for each location relative to the "worst" location: shelf 6 (bottom shelf) of cooler 6 (farthest from entrance), and stratified results by baseline preference.

\section{Sensitivity analyses}

Since our model used particular assumptions and parameters, we conducted a comprehensive set of sensitivity analyses to test the robustness of our results to changing circumstances, assumptions, and variability. Sensitivity analyses varied beverage preference, the baseline probability of being a "convenience shopper" vs. "browser", and the "horizontal" and "vertical" effects. We tested the following five scenarios: 1) increasing the probability that the "always SSB" group purchased a non-SSB up to $25 \%$, 2) doubling the probability of being a "convenience shopper", 3) halving the probability of being a "convenience shopper, 4) doubling the "horizontal" and "vertical" effects simultaneously (i.e., doubling the difference in the probability of purchase between coolers/shelves), and 5) halving the "horizontal" and "vertical" effects simultaneously 
(i.e., halving the difference in the probability of purchase between coolers/shelves).

\section{Results}

Figure 2 shows the probability of purchasing a non-SSB for each shelf of each cooler relative to the "worst" location (cooler 6, shelf 6). Our model indicates that the optimal location was in cooler 1 (closest to the store entrance), on shelf 2 and 3 (at approximately eye level). A non-SSB placed here was 2.8 times more likely to be purchased compared to the worst location. A non-SSB placed on any shelf in the first cooler was more likely to be purchased than in coolers $2-6$. Even on the bottom shelf of the first cooler, a non-SSB is projected to be 2.5 times more likely to be purchased compared to the worst location. Among the remaining coolers 2 through 6 , cooler 2 , shelf 2 was the second most optimal location (1.3 times greater than worst location).

Figure 3 stratifies the relative probability of purchase by beverage preference. The effect of product placement was strongest among "sometimes SSB" drinkers: they were 4.9 times more likely to purchase non-SSBs in the optimal location compared to the worst location. While product placement had a modest effect on "usually SSB" and "rarely/never SSB" drinkers, we found no effect among "always SSB" drinkers.

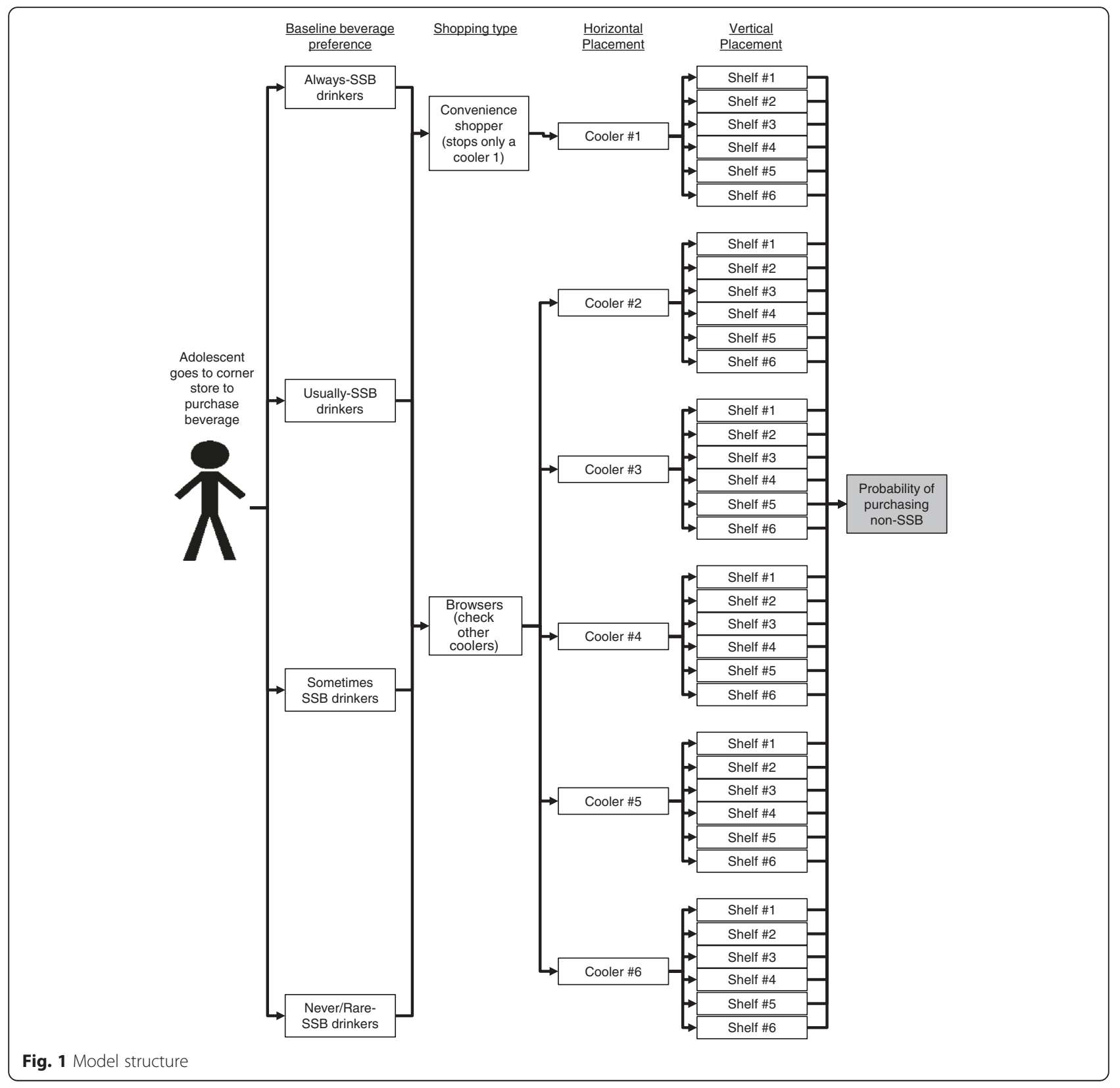


Table 1 Model Input parameters and values

\begin{tabular}{|c|c|c|}
\hline Parameter & $\begin{array}{l}\text { Probability of } \\
\text { non-SSB purchase }\end{array}$ & Source \\
\hline \multicolumn{3}{|l|}{ Base preference Probability } \\
\hline Always SSB & 0 & [9] \\
\hline Usually SSB & $0-28.4$ & [9] \\
\hline Sometimes SSB & $28.5-54.4$ & [9] \\
\hline Rare/never SSB & $>54.4$ & [9] \\
\hline \multicolumn{3}{|c|}{ “Convenience shopper” Probability } \\
\hline Baseline "convenience shopper" & 32.6 & [11] \\
\hline \multicolumn{3}{|l|}{ Loyalty } \\
\hline Always SSB & 27.0 & [5] \\
\hline Usually SSB & 75.0 & {$[5]$} \\
\hline Sometimes SSB & 100.0 & {$[5]$} \\
\hline Rare/never SSB & 27.0 & {$[5]$} \\
\hline \multicolumn{3}{|l|}{ Horizontal Effect ${ }^{b}$} \\
\hline Cooler 1 & 17.9 & [7] \\
\hline Cooler 2 & 17.4 & [7] \\
\hline Cooler 3 & 16.9 & [7] \\
\hline Cooler 4 & 16.4 & [7] \\
\hline Cooler 5 & 15.9 & [7] \\
\hline Cooler 6 (back) & 15.4 & [7] \\
\hline \multicolumn{3}{|l|}{ Vertical Effect ${ }^{\mathrm{b}}$} \\
\hline Shelf 1 (top) & 17.0 & [7] \\
\hline Shelf 2 & 17.2 & [7] \\
\hline Shelf 3 & 17.1 & [7] \\
\hline Shelf 4 & 16.8 & [7] \\
\hline Shelf 5 & 16.3 & [7] \\
\hline Shelf 6 & 15.5 & [7] \\
\hline \multicolumn{3}{|c|}{$\begin{array}{l}\text { Notes: } \\
\text { aProbabilities of being a convenience shopper were calculated as the product } \\
\text { of the baseline probability of being a convenience shopper and the } \\
\text { probabilities associated with brand loyalty for each type of SSB drinker } \\
{ }^{b} \text { Horizontal and Vertical effects were calculated based upon regression } \\
\text { coefficient parameters obtained from [7] and average retail beverage } \\
\text { cooler dimensions }\end{array}$} \\
\hline
\end{tabular}

Assuming that beverage preferences and purchases from the BHCK sample are representative of Baltimore's adolescent population [13], we extrapolate our findings to project the increase in non-SSBs purchased by all Baltimore adolescent over the course of a year under 3 scenarios: moving non-SSBs from the worst to optimal position; moving non-SSBs from the worst to second most optional location; and moving non-SSBs from the second most optional to optimal location. We project that the first scenario would result 5.2 million more non-SSBs, Scenario 2 would result in an approximate 700,000 more non-SSBs, and scenario 3 would result in 366,000 more non-SSBs purchased by Baltimore adolescents.

Sensitivity analyses suggested that our results are overall robust to potential mismeasurement of preference and shopping behaviors. Sensitivity analysis results are show in Table 2. Cooler 1 , shelf 2 and 3 remained the optimal positions, but the relative magnitude of increases in non-SSB purchases changed slightly. While our model appeared to be most sensitive to changes in the convenience shopper parameter, results remained consistent and within the same order of magnitude as our original results (Fig. 2). For example, even when we halved the "convenience shopper" parameter, adolescents are still nearly twice as likely to purchase a non-SSB in the optimal location compared to the worst location. Changes the other parameters ("always SSB" probability, and horizontal and vertical effects) resulted in a range of relative probabilities of purchase from 2.5 to 3.5 in the optimal location (cool 1, shelf 2 or 3 ) compared to worst location.

\section{Discussion}

Our study assessed product placement as public health strategy to improve beverage purchases. It is the first to quantify the potential impact of changing non-SSB placement in corner stores and suggests that this could be an effective strategy for populations highly susceptible to childhood and adolescent obesity. The strongest effect occurred among individuals who sometimes drank SSBs, suggesting that this nudging technique might be most effective in preventing weight gain in a population who might be at the verge of developing this unhealthy habit or are considering changing bad habits. Our results do not suggest that product placement should be the only interventions. For example, those who always drink SSBs will need other public health strategies (e.g., education, soda tax) to alter their beverage preferences before nudging interventions can be effective.

While the parameters and assumptions of our model came from studies that were not conducted in SSBs or other sugary foods that may potentially be habit-forming [14], we conducted a variety of sensitivity analyses to assess how changes to these parameters and assumptions might alter our results. Although the relative probabilities of purchased changed in our sensitivity analyses, these results were still within a similar order of magnitude to our baseline model. To our knowledge, data on SSBs or other similar sugary products that can be used to parameterize our model does not exist, but our sensitivity analyses gives us confidence that we would observe similar results. Although our model may overestimate the effects of product placement on non-SSB purchases for some portion of the population - particularly "always" and "usually SSB" drinkers who may be more willing to seek out SSBs - our findings will still apply to the majority of the population who only occasionally drinks SSBs [15]. Additionally, other studies have found that product placement, such as the physical distance from a serving bowl, or placement by the cash register, 


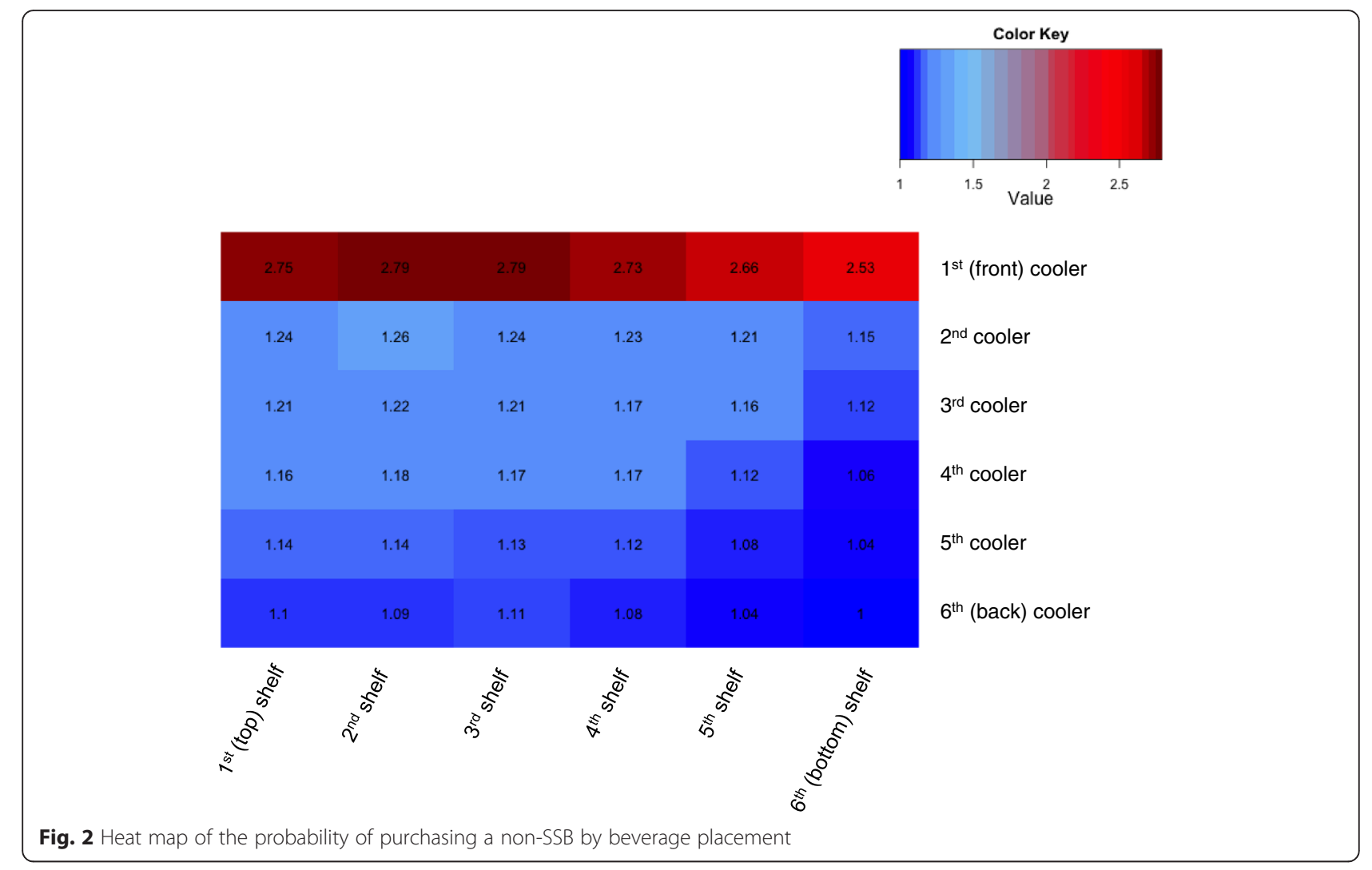

\begin{tabular}{|c|c|c|c|c|c|c|c|c|c|c|c|}
\hline & & & & & & & & & & & Color Key \\
\hline & Rarely & never & SSB & & & & ometin & nes $S$ & & & $12^{2}$ Value ${ }^{4}$ \\
\hline 1.95 & $15 \quad 1.98$ & 1.97 & 1.95 & 1.87 & 1.8 & 4.73 & 4.81 & 4.92 & 4.71 & 4.69 & Front $\left(1^{\text {st }}\right)$ cooler \\
\hline 1.23 & $23 \quad 1.25$ & 1.23 & 1.22 & 1.21 & 1.15 & 1.29 & 1.28 & 1.26 & 1.24 & 1.24 & $2^{\text {nd }}$ cooler \\
\hline 1.21 & $21 \quad 1.21$ & 1.21 & 1.17 & 1.15 & 1.11 & 1.23 & 1.22 & 1.24 & 1.17 & 1.19 & $3^{\text {rd }}$ cooler \\
\hline 1.18 & 1.19 & 1.16 & 1.15 & 1.13 & 1.07 & 1.16 & 1.19 & 1.2 & 1.21 & 1.1 & $4^{\text {th }}$ cooler \\
\hline 1.14 & $14 \quad 1.14$ & 1.14 & 1.12 & 1.09 & 1.03 & 1.14 & 1.16 & 1.17 & 1.15 & 1.08 & $5^{\text {th }}$ cooler \\
\hline & $1 \quad 1.09$ & 1.12 & 1.08 & 1.05 & 1 & 1.12 & 1.11 & 1.14 & 1.07 & 1.06 & Back $\left(6^{\text {th }}\right)$ cooler \\
\hline & Usuall! & SSB & & & & & Iways & SSB & & & \\
\hline 3.6 & $\begin{array}{ll}6 & 3.62\end{array}$ & 3.62 & 3.53 & 3.46 & 3.25 & & 0 & 0 & 0 & 0 & Front $\left(1^{s t}\right)$ cooler \\
\hline 1.23 & $\begin{array}{ll}23 & 1.27\end{array}$ & 1.25 & 1.26 & 1.18 & 1.14 & & 0 & 0 & 0 & 0 & $2^{\text {nd }}$ cooler \\
\hline 1.2 & 1.24 & 1.2 & 1.19 & 1.16 & 1.11 & D & 0 & 0 & 0 & 0 & $3^{\text {rd }}$ cooler \\
\hline 1.14 & 1.16 & 1.17 & 1.19 & 1.11 & 1.05 & & 0 & 0 & 0 & 0 & $4^{\text {th }}$ cooler \\
\hline 1.13 & $13 \quad 1.12$ & 1.1 & 1.12 & 1.07 & 1.05 & & 0 & 0 & 0 & 0 & $5^{\text {th }}$ cooler \\
\hline 1.1 & 11.1 & 1.08 & 1.08 & 1.02 & 1 & & & & & 0 & Back (6 $\left.6^{\text {th }}\right)$ cooler \\
\hline 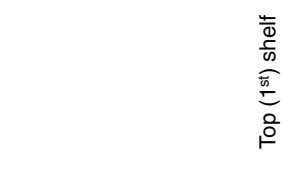 & 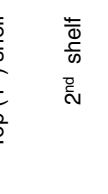 & 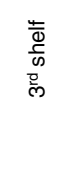 & $\begin{array}{l}\frac{\hbar}{\frac{\omega}{0}} \\
\frac{5}{6} \\
\frac{f}{\sigma}\end{array}$ & 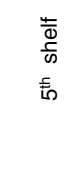 & 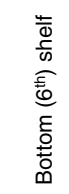 & 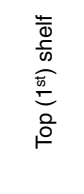 & $\begin{array}{l}\frac{t}{\mathrm{w}} \\
\frac{\mathrm{c}}{50} \\
\stackrel{ \pm}{\mathrm{N}}\end{array}$ & 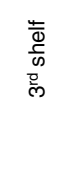 & $\begin{array}{l}\frac{t}{\frac{\omega}{\omega}} \\
\frac{\omega}{\omega} \\
\frac{f}{\sigma}\end{array}$ & $\begin{array}{l}\frac{t}{\bar{c}} \\
\frac{\omega}{\omega} \\
\text { t) }\end{array}$ & 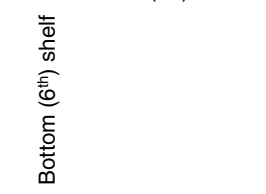 \\
\hline
\end{tabular}


Table 2 Sensitivity analysis parameters and results

\begin{tabular}{|c|c|c|c|c|c|}
\hline \multirow{2}{*}{$\begin{array}{l}\text { Variable } \\
\text { Convenience shopper }\end{array}$} & \multicolumn{4}{|l|}{ Probability } & \multirow{2}{*}{$\begin{array}{l}\text { Relative probability of } \\
\text { purchase in the optimal } \\
\text { location compared to } \\
\text { the worst location }{ }^{a} \\
1.97\end{array}$} \\
\hline & \multicolumn{4}{|l|}{18.3 (half) } & \\
\hline & \multicolumn{4}{|l|}{65.2 (double) } & 5.01 \\
\hline Always SSB & \multicolumn{4}{|l|}{25} & 3.50 \\
\hline \multirow[t]{14}{*}{ Horizontal and Vertical effects } & \multicolumn{2}{|c|}{ Vertical (double) } & \multicolumn{2}{|c|}{ Horizontal (double) } & 3.47 \\
\hline & Shelf 1 (top) & 17.4 & Cooler 1 & 19.2 & \\
\hline & Shelf 2 & 17.8 & Cooler 2 & 18.2 & \\
\hline & Shelf 3 & 17.6 & Cooler 3 & 17.2 & \\
\hline & Shelf 4 & 17.0 & Cooler 4 & 16.2 & \\
\hline & Shelf 5 & 16.0 & Cooler 5 & 15.2 & \\
\hline & Shelf 6 & 14.4 & Cooler 6 (back) & 14.2 & \\
\hline & \multicolumn{2}{|l|}{ Vertical (half) } & \multicolumn{2}{|l|}{ Horizontal (half) } & 2.51 \\
\hline & Shelf 1 (top) & 17.1 & Cooler 1 & 17.3 & \\
\hline & Shelf 2 & 16.9 & Cooler 2 & 17.0 & \\
\hline & Shelf 3 & 16.9 & Cooler 3 & 16.8 & \\
\hline & Shelf 4 & 16.7 & Cooler 4 & 16.5 & \\
\hline & Shelf 5 & 16.5 & Cooler 5 & 16.3 & \\
\hline & Shelf 6 & 16.1 & Cooler 6 (back) & 16.0 & \\
\hline
\end{tabular}

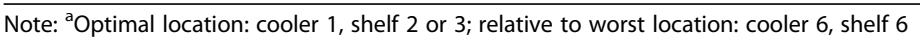

affects consumption of sugary snack foods that may be similarly habit forming, including ${\mathrm{M} \& M s^{\circ}}^{\circ}$ [8], cereal bars [16], and animal crackers [17]. This suggests that product placement does affect consumption behavior across a variety of products, including sugary, habitforming products.

Some corner stores may have cooler space limitations (e.g., beverage suppliers may purchase or reserve optimal cooler space), and certain placement locations may not be available. We present our results in the form of a heat map, a simple visual tool that shows the effect of product placement for the entire cooler space. This heat map will allow corner store owners and other interested stakeholders, such as public health researchers and policy makers, to identify possible non-SSB product placement locations given a corner store's specific space constraints. Since store owners negotiate stocking based upon store profit, a successful product placement intervention should increase demand for non-SSBs, which in turn, may encourage store owners to both place non-SSBs in more easily accessible locations and increase the stocking of non-SSBs. Additionally, understanding the potential of product placement on healthier beverage consumption is valuable to a variety of stakeholders, such as public health researchers, and can help inform other interventions that take advantage of marketing tools and nudging techniques.

While computational models are simplifications of real life and may not account for all of the factors that may affect purchasing decisions (e.g., beverage prices and sizes, number of beverage facings, familiarity with beverages over time) $[8,14,16,17]$, they serve as method to merge disparate data from various sources to test hypotheses that may take considerable time, effort, and resources to test in natural settings. Many industries including advertisers and marketers utilize computational models to plan their strategies before executing them. A computational model is particularly apt to assess the potential of this intervention in a corner store setting given their limited technological and human resources, which would make conducting an evaluation challenging and with limited generalizability. Results from our computational model should be used in conjunction with and to help inform future quasi-experimental studies or intervention evaluation.

\section{Conclusions}

Our model suggests that placing non-SSBs at the front of the store, at approximately eye level, may "nudge" individuals, particularly those who occasionally drink SSBs towards healthier beverage choice. These results are an initial step in exploring product placement's potential and can guide the future implementation of this lowcost public health intervention.

Competing interests

The authors declare that they have no competing interests. 


\section{Authors' contributions}

MSW, CN, AYK, LC, and BYL developed the initial research question and model. AYK, GMV, and JG assisted with model population and calibration. All authors helped analyze and interpret the results, contributed to the writing and revising of the manuscript, and approved the final manuscript.

\section{Acknowledgements}

We would like to thank Sarah Rastatter, Kate Perepezko, Sarah Lange, Donna Dennis, Kelleigh Eastman, Hye Min Kim, Yeeli Mui, Alessandra Grasso, Ron Saxton, Angelica Cristello, Morgan McCloskey Angela Trude, Melissa Sattler, Maggie Leathers, Eunkyung Han, Dennis Kim, Yan Kharmats, Urshila Sriram, Tracy Yang, JaWanna Henry, Laura Hopkins, Betsy Anderson, Cara Shipley, and Sarah Bartch.

Supported by the Global Obesity Prevention Center (GOPC) at Johns Hopkins, and the Eunice Kennedy Shriver National Institute of Child Health and Human Development (NICHD) and the Office of the Director (OD), National Institutes of Health, under award U54HD070725 and under award U01HD086861. The content is solely the responsibility of the authors and does not necessarily represent the official views of the National Institutes of Health.

\section{Author details}

'Global Obesity Prevention Center (GOPC) and Johns Hopkins, Johns Hopkins School of Public Health, 615 N. Wolfe St, Baltimore, MD 21205, USA.

${ }^{2}$ Department of Health Policy and Management, Johns Hopkins School of Public Health, 624 N. Broadway, Baltimore, MD 21205, USA. ${ }^{3}$ Department of International Health, Johns Hopkins School of Public Health, $615 \mathrm{~N}$. Wolfe St, Baltimore, MD 21205, USA. ${ }^{4}$ Health and Society Institute, Baixada Santista Campus, Federal University of Sao Paulo, 136 Silva Jardim Street, Santos, SP 11015-020, Brazil. ${ }^{5}$ Johns Hopkins Weight Management Center, Johns Hopkins School of Public Health, 550 N. Broadway, Suite 1001, Baltimore, MD 21205, USA. ${ }^{6}$ Department of Health, Behavior \& Society, Johns Hopkins Weight Management Center, Johns Hopkins School of Public Health, $615 \mathrm{~N}$. Wolfe St, Baltimore, MD 21205, USA. 'Department of International Health, Center for Human Nutrition, Johns Hopkins School of Public Health, $615 \mathrm{~N}$. Wolfe St, Baltimore, MD 21205, USA.

Received: 18 September 2015 Accepted: 16 December 2015

Published online: 23 December 2015

\section{References}

1. Shaffer G. Slotting allowances and optimal product variety. Advances in Economic Analysis and Policy. 2005:5(1):1-3.

2. Malik VS, Schulze MB, Hu FB. Intake of sugar-sweetened beverages and weight gain: A systematic review. Am J Clin Nutr. 2006;84(2):274-88.

3. Kleef E, Broek O, Trijp H. Exploiting the Spur of the Moment to Enhance Healthy Consumption: Verbal Prompting to Increase Fruit Choices in a Self-Service Restaurant. Applied Psychology: Health and Well-Being. 2015;7(2):149-66.

4. van Kleef E, Otten K, van Trijp HC. Healthy snacks at the checkout counter: A lab and field study on the impact of shelf arrangement and assortment structure on consumer choices. BMC Public Health. 2012;12(1):1072

5. Yim CK, Kannan P. Consumer behavioral loyalty. J Bus Res. 1999:44(2):75-92.

6. Drèze $X$, Hoch SJ, Purk ME. Shelf management and space elasticity. J Retail. 1994;70(4):301-26.

7. Van Nierop E, Fok D, Franses PH. Interaction between shelf layout and marketing effectiveness and its impact on optimizing shelf arrangements. Mark Sci. 2008:27(6):1065-82.

8. Maas J, de Ridder DT, de Vet E, De Wit JB. Do distant foods decrease intake? The effect of food accessibility on consumption. Psychol Health. 2012; 27(sup2):59-73.

9. Gittelsohn J, Steeves EA, Mui Y, Kharmats AY, Hopkins LC, Dennis D. B'More healthy communities for kids: design of a multi-level intervention for obesity prevention for low-income African American children. BMC Public Health. 2014;14(1):942.

10. Google Shopping Retail Beverage Coolers. https://www.google.com/ webhp? sourceid $=$ chrome-instant\&ion $=1 \&$ espv $=2 \&$ ie $=U T F-8 \# q=$ retail +beverage+cooler\&tbm=shop. Accessed 2 March 2015.

11. Wansink B, Hanks AS. Slim by design: Serving healthy foods first in buffet lines improves overall meal selection. PLoS One. 2013;8(10):e77055.
12. Centers for Disease Control and Prevention. The CDC guide to strategies for reducing the consumption of sugar-sweetened beverages. Atlanta: CDC; 2010

13. U.S. Census Bureau. American Fact Finder. 2014.

14. Zhen C, Wohlgenant MK, Karns S, Kaufman P. Habit formation and demand for sugar-sweetened beverages. Am J Agric Econ. 2011;93(1):175-93.

15. Centers for Disease Control and Prevention (CDC). Beverage consumption among high school students — United States, 2010. MMWR Morb Mortal Wkly Rep. 2011;60(23):778-80.

16. Keller C, Markert F, Bucher T. Nudging product choices: The effect of position change on snack bar choice. Food Qual Prefer. 2015;41:41-3.

17. Musher-Eizenman DR, Young KM, Laurene K, Galliger C, Hauser J, Oehlhof MW. Children's sensitivity to external food cues: How distance to serving bowl influences children's consumption. Health Educ Behav. 2010;37(2):186-92.

\section{Submit your next manuscript to BioMed Central and we will help you at every step:}

- We accept pre-submission inquiries

- Our selector tool helps you to find the most relevant journal

- We provide round the clock customer support

- Convenient online submission

- Thorough peer review

- Inclusion in PubMed and all major indexing services

- Maximum visibility for your research

Submit your manuscript at www.biomedcentral.com/submit 